\title{
Oftalmomiíase externa causada por Dermatobia hominis
}

\section{Dermatobia hominis provoking external ophthalmomyiasis}

Abelardo de Souza Couto Junior¹, Jociana Paludo², Fernanda de Souza Santana², Márcio Neves Leão², Maria de Fátima Pinheiro Gonçalves ${ }^{3}$

\section{ResUMO}

Relato de caso de oftalmomíase externa em uma paciente de 82 anos, diabética e hipertensa, residente na zona rural, que inicialmente apresentava um quadro sugestivo de celulite pré-septal e hordéolo, com dor, edema, eritema e nodulação localizada na pálpebra superior e bulbo ocular normal. Foi então tratada com antibiótico e corticóide local, que levou a redução do processo inflamatório, possibilitando a realização de adequado exame físico, com a eversão da pálpebra superior, sendo estabelecido o diagnóstico de oftalmomiíase externa. Após tentativa frustrada de retirada ambulatorial da larva, foi indicado o procedimento cirúrgico por uma incisão vertical no tarso, a qual possibilitou a remoção de larva de $6 \mathrm{~mm}$ de comprimento, com características da espécie Dermatobia hominis. Diante do exposto, é importante destacar, os vários diagnósticos diferenciais de oftalmomiíase, a particularidade de cada agente, as formas possíveis de tratamento, os fatores de risco e aspectos profiláticos.

Descritores: Miíase; Infecções oculares parasitárias/terapia; Pálpebras; Ivermectina/ uso terapêutico; Relatos de casos

\footnotetext{
'Doutor, Professor Titular de Oftalmologia da Faculdade de Medicina de Valença - FMV - Valença (RJ), Brasil; Coordenador da Residência Médica em Oftalmologia do Instituto Benjamin Constant - Ministério da Educação; ${ }^{2}$ Acadêmicos do $11^{\circ}$ período da Faculdade de Medicina de Valença - FMV - Valença ( RJ), Brasil; ${ }^{3}$ Professora Adjunta de Parasitologia Médica I e II da Faculdade de Medicina de Valença - FMV - Valença (RJ), Brasil.
}

Trabalho realizado na Faculdade de Medicina de Valença (FMV). Valença (RJ), Brasil. 


\section{INTRODUÇÃO}

$\mathbf{M}$ iíase é a infestação dos órgãos e tecidos do homem e animais por larvas de moscas, da ordem díptera, por um período de tempo. Estas larvas se alimentam de tecidos vivos ou necróticos, ou de nutrientes ingeridos pelo hospedeiro ${ }^{(1)}$. Os dípteros podem ser divididos em 3 grupos: obrigatórios, facultativos e pseudomiíase. As obrigatórias são aquelas que se desenvolvem sobre ou dentro de vertebrados vivos, têm caráter invasivo e o homem pode ser seu hospedeiro principal. As facultativas são larvas de dípteros que se desenvolvem em matéria orgânica em decomposição e podem atingir tecido humano necrosado, porém causando uma infecção mais tênue. E a pseudomiíase é ocasionada por larvas de dípteros ingeridas com alimentos ${ }^{(2)}$.

Existem duas formas clínicas de miíase, produzidas por larvas biontófagas: furunculóide e cavitária. $\mathrm{Na}$ primeira, a etiologia é devida às espécies: Dermatobia hominis e Callitroga hominivorax. Já, na cavitária, a espécie mais comum é a Callitroga hominivorax e esta atinge cavidades, como cavidade nasal, seios paranasais, conduto auditivo ${ }^{(3)}$. Essas duas espécies são as mais frequentes nos trópicos, portanto no Brasil (1). A míase provocada pela Dermatobia hominis geralmente é causada por uma só larva, enquanto a miíase causada pela Callitroga hominivorax promove inflamação menos localizada, com inúmeras larvas, que possuem movimentação ativa, no mesmo sítio de infestação ${ }^{(1)}$.

O envolvimento da região óculo-palpebral é raro, podendo acontecer em aproximadamente $5 \%$ dos casos, resultando em acometimento variável, desde irritação local até cegueira, desfiguração e morte ${ }^{(1)}$. A oftalmomiíase geralmente tem como vetor as moscas: Musca dosmestica, presente nos domicílios; Fannia, presente no lixo; e Oestrus ovis, a mosca de ovelhas ${ }^{(4)}$. As moscas, geralmente, depositam seus ovos na margem palpebral ou no canto interno e a larva pode permanecer na superfície do olho, causando irritação, dor, hiperemia conjuntival, ou pode afetar os tecidos intraoculares ou orbitais mais profundos ${ }^{(4)}$. Desta forma, a infecção pode ser classificada como: oftalmomiíase externa, quando acomete a órbita ou os tecidos oculares anexos; oftalmomiíase interna anterior, quando há envolvimento da câmara anterior do olho; oftalmomíase interna posterior, quando a larva acomete o segmento posterior $^{(1)}$.

O diagnóstico diferencial de oftalmomiíase externa inclui todas as doenças, oculares ou sistêmicas, que evoluem com celulite pré-septal orbitária, tais como: conjuntivite, corpo estranho, hordéolo, abcesso palpebral, sinusopatia, neoplasias e erisipela palpebral ${ }^{(4)}$.

O diagnóstico de várias afecções oculares e mesmo da oftalmomiíase pode ser prejudicado devido ao intenso processo inflamatório periorbitário que dificulta o exame clínico adequado.

O objetivo deste é relatar um caso de portador de oftalmomiíase externa, discorrendo sobre o quadro clínico, os diagnósticos diferenciais e as opções de tratamento.

\section{Relato de Caso}

MMR, 82 anos, branca, natural de Andrelândia/ MG, residente na zona rural, iniciou quadro de sinais irritativos no olho direto, incluindo hiperemia, prurido e secreção purulenta que, ao acordar, não dificultava a abertura do olho. A paciente é hipertensa em tratamento há 12 anos, e diabética tipo 2, há 8 anos. Nega etilismo e tabagismo. Reside em casa com saneamento básico adequado e com a presença de diversos tipos de animais.

Após uma semana do início dos sintomas, a paciente procurou atendimento, tendo sido diagnosticado conjuntivite e realizado tratamento, sem melhora. Houve intensificação dos sintomas, piora do edema que se estendeu para a região periorbitária, frontal e maxilar direita. Observou-se madarose dos cílios ipsilateral e sinais irritativos em olho contralateral, porém com ausência de edema e secreção purulenta.

Com este quadro, a paciente foi encaminhada ao Ambulatório de Oftalmologia da Faculdade de Medicina de Valença. O intenso processo inflamatório dificultava o exame físico adequado. Foi então, diagnosticada uma celulite pré-septal de etiologia indeterminada e feita injeção de $0,1 \mathrm{ml}$ de triancinolona $10 \mathrm{mg} / \mathrm{ml}$ perilesional, além de cefalexina $500 \mathrm{mg}$ por via oral, de 6/6 horas durante 7 dias. Após o $3^{\circ}$ dia de tratamento, houve redução da inflamação, restando um abaulamento no terço médio da pálpebra superior, com um orifício de drenagem externa.

Na segunda consulta ao oftalmologista, quando foi possível realizar a eversão da pálpebra superior, foi feito o diagnóstico de oftalmomíase externa devido à observação da movimentação da larva no orifício tarsal. Procedeu-se a oclusão do orifício com pomada oftálmica e uso de pinça, sem sucesso. $\mathrm{O}$ passo seguinte foi a indicação do procedimento cirúrgico, realizado sob assepsia e antissepsia com polvidine tópico e anestesia local com xilocaína 2\% e adrenalina 1:200.000. Após a eversão da pálpebra superior foi feita uma incisão vertical no tarso (Figura 1), sobre a lesão, a qual possibilitou a retirada de uma larva de cerca de $6 \mathrm{~mm}$ de compri- 


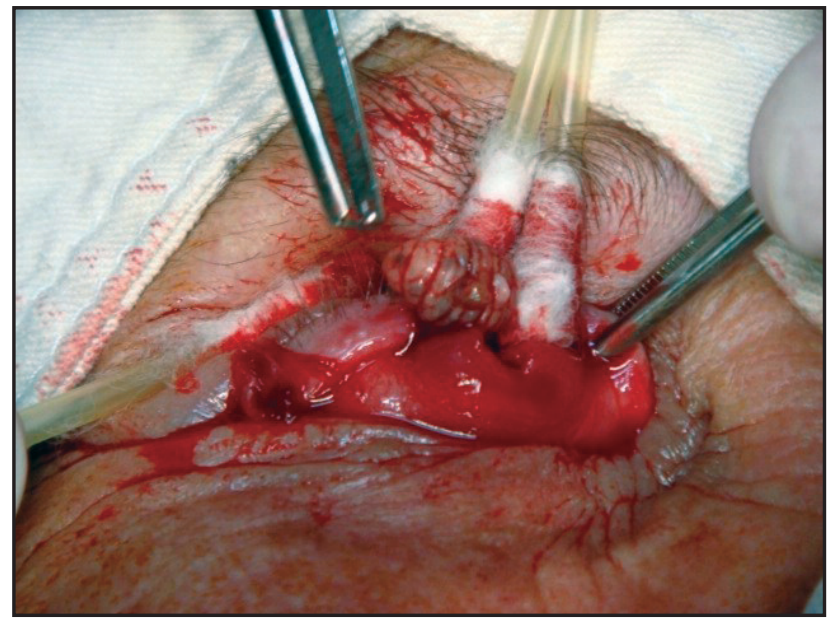

Figura 1: Incisão vertical no tarso após eversão da pálpebra superior

mento (Figura 2). A larva foi encaminhada ao Serviço de Parasitologia da Faculdade de Medicina de ValençaRJ, sendo identificada como Dermatobia hominis. A cicatrização do tarso ocorreu por segunda intenção, não sendo realizada a sutura do tarso.

\section{Discussão}

Muitas espécies diferentes de moscas podem produzir miíase. O tecido ocular pode ser afetado por transmissão mecânica e/ou pela atividade parasitária da larva $^{(4)}$.A larva consegue invadir tanto o tecido necrosado, quanto o saudável. Muitas pessoas tornam-se infectadas por ingestão acidental de ovos ou larvas, ou ainda, por contaminação ou ferida externa da pele.

A paciente em questão era idosa e diabética. É conhecido que bebês e crianças pequenas, alcoólatras, pacientes debilitados não tratados, como diabéticos e deficientes mentais, pessoas de nível socioeconômico menos privilegiado, e habitantes de zona rural são alvos comuns a infestação com as moscas produtoras de míase ${ }^{(1,2,4)}$.

No presente caso, a forma clínica de apresentação assemelha-se a forma furunculóide, caracterizada pela formação de nódulos subcutâneos típicos onde, ocasionalmente, podem ocorrer infecções bacterianas e formação de abscessos ${ }^{(5)}$.

Foi feita a injeção de triancinolona e antibioticoterapia oral devido a suspeita clínica de celulite pré-septal e hordéolo.

A celulite pré-septal é uma afecção dos tecidos periorbitários causada pela introdução de material contaminado através da pele ou por infecção endógena dos

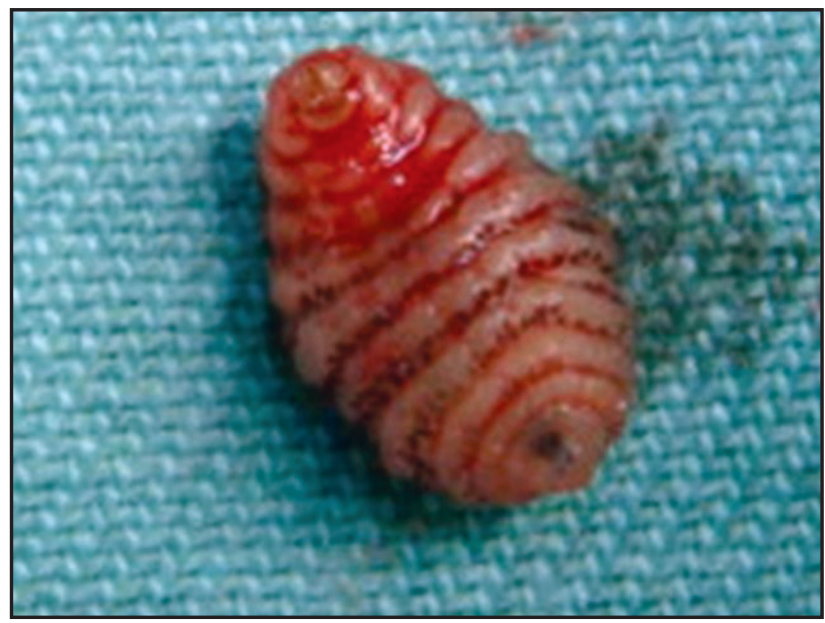

Figura 2: Larva da espécie D. hominis retirada da pálpebra da paciente

seios paranasais ${ }^{(1)}$. No relato, o que levou a se pensar em celulite pré-septal e hordéolo foram as queixas de dor e os sinais de edema, eritema e nodulação, localizados na pálpebra superior e bulbo ocular normal. Não foi possível na primeira consulta verificar nenhum orifício de entrada que possibilitasse a suspeita de oftalmomiíase, devido a intensa flogose e dificuldade de eversão da pálpebra.

Existem diversos procedimentos descritos para a retirada de larvas. O mais simples é a retirada mecânica, com pinça e compressão sobre a área edematosa, que é uma boa opção nos casos com poucas larvas ou larva única ${ }^{(2)}$.

Pode ser considerado o desbridamento cirúrgico e outras alternativas como tentativa de bloquear a respiração da larva, utilizando substâncias como vaselina, pomadas, éter, álcool e outros, atraindo a larva para a superfície, o que facilita sua retirada ${ }^{(2)}$.

No caso relatado, a infestação se deu por uma única larva, diagnosticada como D. hominis, como citado na literatura ${ }^{(1)}$. A oclusão do orifício foi tentada com pomada oftálmica e uso de pinça de conjuntiva, sem resultado favorável, partindo-se para a retirada cirúrgica, feita após anestesia local com xilocaína $2 \%$ e adrenalina 1:200.000, uma vez que se tratava de sítio aparentemente único e de fácil acesso (oftalmomíiase externa). A conduta é mais complexa quando há envolvimento por várias larvas e em local de difícil acesso, como a órbita. Nestas condições, o tratamento consiste no uso de ivermectina oral, com retirada das larvas mortas e reconstrução dos tecidos afetados ou até mesmo exenteração quando há necrose extensa e irreparável dos tecidos orbitários ${ }^{(2)}$. 
A miíase por inúmeras larvas no mesmo sítio de infestação geralmente é causada pela C. hominivorax ${ }^{(1)}$. Takahagi et al. relataram a retirada mecânica de 17 larvas de C. hominivorax, localizadas em sítios diferentes ${ }^{(1)}$. Iankilevicz et al. (2007) apresentaram um caso de oftalmomiíase externa em recém-nascido, do qual foram retiradas seis larvas do tipo D. hominis, com cerca de 0,3 a $0,7 \mathrm{~cm}$ de comprimento, sendo cinco na pálpebra superior direita e uma na pálpebra superior esquerda. Não foi relatada a identificação correta da larva neste estudo ${ }^{(6)}$.

O combate a mosca e a melhoria das condições de saneamento básico seriam fatores importantes na prevenção. Como se trata de um parasita de animais, e recomendado o tratamento dos animais e telagem das janelas e portas, principalmente em locais onde habitam pessoas submetidas a intervenção cirúrgica recente ou em condições que permitam a oviposição, por exemplo, machucados externamente. Uma grande contribuição na prevenção é o esclarecimento do paciente e seus familiares sobre a "bicheira" e os cuidados para evitá-la ${ }^{(1)}$.

\section{Conclusão}

Os autores enfatizam a importância do diagnóstico da oftalmomiíase externa, nem sempre comum nos grandes centros urbanos, seu tratamento e evolução.

\section{Abstract}

A 82 years old women reported an external opthalmomyiasis. She was a diabetic and with high blood pressure carrier, living in rural area. Initially a she had pain with swelling, erythema and nodulation located on the upper eyelid and normal eye and a pre-septal cellulitis was suspected and antibiotic and local steroid were introduced, which led to a reduction of inflammatory process and to perform an appropriate physical examination with the eversion of the upper eyelid, which established the diagnosis of an external opthalmomyiasis. After the unsuccessful attempt to outpatient withdrawal of the worm, was appointed the surgical procedure by a vertical incision in the tarsus, which allowed the removal of a larva $6 \mathrm{~mm}$ long, with characteristics of the species Dermatobia hominis. Considering the foregoing, it is important to emphasize, the various differencial diagnostics of opthalmomyiasis, the particularity of each agent, possible forms of treatment, the risk factors and prophylaxis of this disease.

Keywords: Myiasis; Eye infections, parasitic/ therapy; Eyelid; Ivermectin/therapeutic use; Case reports

\section{RefERÊNCIAS}

1. Takahagi RU, Gonçalves FP, Madeira NG, Schellini SA. Oftalmomiíase externa causada por Cochliomyia hominivorax: Rev Bras Oftalmol. 2007; 1(66): 58-62.

2. Pantaleão GR, Oescher RA, Correia RJB, Fischer R, Shiroma HF. Uso de ivermectina como tratamento coadjuvante na mí́ase orbital: Rev Bras Oftalol. 2006; 6(65): 352-5.

3. Moraes RG, Goulart GE. Parasitologia e Micologia Humana: Braquíceros, orthorrhpha cyclorrhapha principais famílias e espécies. 4a ed. Rio de Janeiro: Cultura Médica; 2000. p. 536-7.

4. Vaughan D, Asbury T, Riordan-eva P. Oftalmologia Geral: Conjuntiva. 15a ed. São Paulo: Atheneu; 2003p.105-238.

5. Rey L. Bases da Parasitologia Médica: Dípteros ciclorrafos: As moscas. $2^{\text {a }}$ ed. Rio de Janeiro: Guanabara Koogan; 2002. p.331.

6. Lankilevicz PG, Vieira APIC, Grupenmacher PZ, Sobrinho JRN, Grupenmacher L. Oftalmomíase em recém-nascido de sete dias: Rev Bras Oftalmol. 2007; 3(66): 197-9.

\section{Endereço para correspondência: \\ Abelardo Couto Junior}

Av. N. S. de Copacabana, $n^{\circ} 1.120$ - Gr. 901

CEP 22060-000 - Rio de Janeiro (RJ), Brasil

Telefax: (21) 2521-0645 / 2287-8346.

E-mail: soluc@ig.com.br 